\title{
《建筑装饰施工技术》项目教学法研究
}

\author{
崔维海* \\ 山东省聊城高级工程职业学校, 山东 252000
}

\begin{abstract}
摘 要: 虽然在长时间的教学中已经积累了较多经验, 但是对于《建筑装饰施工技术》复杂的课程内容来讲, 实 际教学难度较大, 目前依然存在较多的问题, 无法达到预期的教学效果。以提高教学质量为目的, 培养学生专业技能 与综合能力, 来灵活应用项目教学法, 通过细节控制, 来有效应对课程特点, 达到最佳教学效果。本文对《建筑装饰 施工技术》教学存在的缺陷进行总结和分析，然后探讨了项目教学法实施要点。
\end{abstract}

关键词：课程教学；项目教学法；建筑装饰施工技术

\section{Research on Project-based Teaching Method of Building Decoration Construction Technology}

\author{
Wei-Hai Cui* \\ Liaocheng Senior Engineering Vocational College, Liaocheng 252000, Shandong, China
}

\begin{abstract}
Although a lot of experience has been accumulated in long-term teaching, the actual teaching of the complex course content of Building Decoration Construction Technology is difficult. At present, there are still many problems that cannot meet the expected teaching effect. In order to improve the quality of teaching, to cultivate students' professional skills and comprehensive abilities, we should flexibly apply project-based teaching methods, effectively deal with the characteristics of the curriculum through detailed control, so as to achieve the best teaching results. This paper summarizes and analyzes the defects in the teaching of Building Decoration Construction Technology, and then discusses the main points of the project-based teaching method.
\end{abstract}

Keywords: Course teaching; project-based teaching method; building decoration construction technology

\section{一、前言}

《建筑装饰施工技术》作为中专教育阶段建筑装饰专业的重要课程之一, 对培养学生建筑装饰施工方面的职业技 能和专业素质具有重要影响。就实际教学效果来看, 课程内容比较抽象和复杂, 涉及众多专业, 包括楼地面工程、 隔墙隔断工程、吊顶工程以及墙面工程等, 学生无任何实践经验, 在学习过程中难度较大, 这就导致课程教学质量较 差。采用项目教学法来进行《建筑装饰施工技术》教学, 是在原有基础上进行改革创新, 以更加科学可行的方法手段 来不断提高教学综合效率。

\section{二、项目教学法特点}

项目教学法即在教师的引领和指导下, 学生独立完成解决一个项目, 争取在解决项目的过程中, 锻炼并培养学生 的专业技能水平以及综合能力, 确保其在掌握基础教学内容的同时, 有较高的专业能力。项目教学法现在在中专教学 中应用越来越广泛, 其具有较强的适应性 ${ }^{[1]}$ 。在实际教学中, 教师根据课程内容来设计教学流程, 指导帮助学生完成 一个项目, 其中学生必须要有独立思考和独立学习的能力, 结合自身实际情况来制定科学可信的学习计划, 约束自身 学习行为，努力克服遇到的一切问题，直到项目完成。

项目教学法实施的关键在于提高学生自主处理问题的能力, 同时完成专业知识点的学习, 灵活掌握并应用专业技 能。实际教学中, 教师可根据课程内容来制定项目计划, 首先进行基础练习, 引导并鼓励学生主动参与项目计划, 独

*通讯作者: 崔维海, 1974年2月, 男, 汉族, 山东荏平人, 就职于山东省聊城高级工程职业学校, 讲师, 本科。 研究方向: 建筑装饰专业教学。 
立完成信息采集与项目执行, 并在最后由教师帮助按成项目评价。整个教学过程中机动性更强, 学生可以通过灵活的 手段来应对和解决遇到的各种问题, 相比传统刻板的教学模式, 项目教学法具有更强的执行效果, 对培养学生自学、 创新以及动手能力意义重大 ${ }^{[2]}$ 。

\section{三、《建筑装饰施工技术》教学现存不足}

(一) 课程特点

《课程装饰施工技术》课程教学的主要目的在于培养学生在建筑施工装饰领域的综合能力, 其涉及地面、墙体、 吊顶、设计造型以及室内门窗等多个方面, 因此教学难度较大, 对学生的要求也比较高。作为一门基础课程, 对学生 职业能力的成长有着密切联系, 必须要采取有效手段来不断提高教学质量。专业课程的教学, 需要重视对学生实践 能力、自主能力的培养, 使其能够在教师的领导下, 熟练掌握各复杂的知识点, 并且具有解决实践问题的能力 ${ }^{[3]}$ 。并 且, 《课程装饰施工技术》还涉及众多的国内外建筑装饰技艺与施工方法, 通过了解学习, 可以进一步拓展学生的视 野，使其对专业特点以及建筑装饰施工有一个更为全面深人的了解。

(二) 教学不足

1. 课程教学与实际脱节

《建筑装饰施工技术》是基础专业课程, 是学生了解认识建筑装饰施工的前提, 对后续的学习有更大的影响。就 目前教学现状来看, 课程多是以建筑装饰施工项目为模块来安排教学项目, 包括墙、柱面装饰, 楼地面, 吊顶以及其 他细部装饰工程施工内容，共分为上下两个学期来学习。

所有项目的教学均是采用分布分项工程讲授的模式, 例如墙面工程共分为抹灰、涂饰、裱糊、块料镶贴、石材干 挂等多个子项目，讲授时各子项目之间关联性不足，缺乏良好的衔接，学生对项目的整体施工过程认知不足 ${ }^{[4]}$ 。

专业培养的应该为项目管理人员而非施工人员，相比技术要点的掌握，更应注重学生对整体项目的把控，可以根 据设计和实际情况来对施工过程进行有效管理, 具有质量验收与问题整改的能力, 而这正是目前教学所欠缺的, 忽视 了对学生该方面的重视。

2. 教学方法不符合需求

对于中专学生来讲, 对于理论知识的学习并不擅长, 并且三维空间想象力较低, 相比而言其对动手解决问题的欲 望更高。《建筑装饰施工技术》虽然是一门基础课程, 但是也涉及众多专业项目, 需要学生多每一个项目甚至每一个 分项均要熟记于心，确定所有施工技术流程与要点的同时，可以对项目整体有一个大体的了解。

很多项目的子任务, 直接就是采用的知识点讲授教学方法, 无法激发学生对知识的兴趣, 无法调动起配合的积极 性, 与学生学习的实际需求有一定差异, 进而无法取得良好的成绩。尤其是很多内容十分抽象、学术, 学生难以理解 和掌握，久而久之对课程就产生畏难的心态，彻底失去对课程学习的兴趣。

想要改变此情况，前提就是根据中专学生的特点，来选择合适的教学方法，激发学生参与以及配合的积极性。

3. 实训环节受限严重

课程实训共包括校外实训与校内实训, 其中校外实训受各种因素的影响非常大, 导致最终无法按照授课计划, 与 安排进度产生较大差异。

对于建筑装饰施工项目来讲, 其一般工期都比较长, 即便是学生有去参加校外实训的机会, 但是到达现场后可以 看到和了解到只有整个项目施工流程中的一部分，并不能看到所有项目及子任务的实操，导致实训的意义降低 ${ }^{[5]}$ 。

随着整个行业的快速发展, 工程所使用的材料以及工艺在快速的更新换代, 而学校因为经费限制往往无法在第一 时间做到同步更新，学生也就没有渠道和机会接触到行业最新材料和施工工艺，课程实训也失去了意义。

\section{四、项目教学法实施要点}

(一) 根据内容完成课程设计

《建筑装饰施工技术》涉及的内容众多, 而实践施工中对每项技术均有着严格要求, 需要严格按照专业规范操 作, 而学生除了要掌握建筑装饰项目施工技术要点以外, 还应对整个施工过程有一个有效的把握, 做好施工安全工 作。因此, 课程教学需要对教学内容进行篮选和整合, 设计科学合理的教学项目, 将教、学、做、评有机结合在一 起，实现理论与实践的有效联合。

课程设计应确定培养学生综合能力为核心, 并加强与各企业的联系, 将实际工程施工引人到项目教学中, 构件教 
学过程, 应用项目教学法与任务驱动法, 向项目不同的环节融入标准、规范、协作以及质量体系的内容, 通过科学的 课程设计, 来实现针对学生能力、职业素养等教学 ${ }^{[6]}$ 。可以充分利用建筑实例、模型以及图片等教学手段, 向学生展 示更加全面、详细的建筑装饰施工过程, 使其能够对建筑装饰构造以及施工技术有更加深人的了解, 更利于教师指导 学生完成教学项目。

结合《建筑装饰施工技术》课程表内容，可将其设计成6个不同学习项目，与 15 个习型工作任务（如表1所示）。 其中, 6 个学习项目是按照由简到繁的原则设计, 更符合中专学生的学习认知规律与职业能力培养的基本规律。通过 对不同教学内容的科学划分, 最大程度上来实现教、学、练、做、评的有机结合, 利用大量的实践操作与反复练习来 促使学生对学科内容有更加全面深人的了解，掌握建筑装饰施工技术要点，并对工程管理有一个初步的认知。

\section{表1 学习项目设计表}

\begin{tabular}{|c|c|c|c|}
\hline 项目名称 & 学习任务 1 & 学习任务 2 & 学习任务 3 \\
\hline 楼地面施工 & 整体类地面施工 & 块材类地面施工 & 其他地面施工 \\
\hline 墙面施工 & 软包工程施工 & 饰面类施工 & 涂料工程施工 \\
\hline 吊顶施工 & 明龙骨顶棚施工 & 暗龙骨顶棚施工 & \\
\hline 隔墙隔断工程 & 隔墙工程施工 & 隔断工程施工 & \\
\hline 门窗工程 & 木门施工 & 金属门窗施工 & \\
\hline 幕墙工程 & 玻璃幕墙施工 & 石材幕墙施工 & 金属幕墙施工 \\
\hline
\end{tabular}

(二) 设计项目方案

根据课程内容模拟一个建筑装饰相关项目工程, 以吊顶工程为例, 项目工程天棚吊顶工程量共分为: 轻钢龙骨 （UC381440 ×440龙骨）、8 mm厚的纸面石膏板以及面漆（乳胶漆）。另外，还包括灯带形式与尺寸、格栅片规格与 颜色等, 并确定所有装饰材料的安装方式。在确定学习项目以后, 第二个阶段就是在教师的指导与帮助下, 促使学生 独立完成项目计划。吊顶项目教师可将学生分为多个小组，按照教学方案与计划来分配并布置学生各自的工作。

1. 项目计划开始前, 教师应引导学生对理论知识进行学习和复习, 向学生讲述与项目相关的理论知识系统, 使其 能够最大程度上与学习项目联系起来，便于对吊顶工程项目施工技术与施工流程的研究与掌握 ${ }^{[]}$。

2. 教师可以组织或者学生自发组织去一个建筑吊顶装饰施工项目的现场进行参观学习, 以更直观的方式来了解施 工内容和技术要点。并且在现场还可以就存疑的部分与施工人员或管理人员进行交流沟通，更全面的了解专业知识， 在掌握理论知识的同时，强化对实践技术的理解。

3. 对已经完工的吊顶工程项目进行参观，对比分析不同形式吊顶的设计要点与施工工艺，有学生自己来发现问 题, 并提出各自应对思路, 这样不仅可以更好的激发学生学习的情绪, 同时也可以促使其对学习过的理论知识进行利 用，更利于对专业知识的掌握。

4. 通过互联网或图书馆查询, 来确定建筑吊顶工程施工工艺与具体流程, 更加清晰明确的了解工程施工所应用到 的材料规格、施工流程、施工技术、工艺方法、质量与安全等, 可以对项目工程有更加全面深人的掌握, 更便于其管 理思维的形成，即除了对施工技术的了解以外，更注重对项目工程整体施工过程的把控，提高其专业素养。

(三) 学习项目实施

在做好前期设计和准备后, 便可而进人到项目教学法中最为重要的实施阶段, 同时也是教学的难点。对于中专学 生来讲, 学习《建筑装饰施工技术》阶段, 其并无独立能力来完成学习项目, 更重要的是要有教师的指导与帮助。本 次吊顶项目，将学生工分为三个组别，分别负责吊顶吊杆、龙骨与石膏板安装、灯带布置三个部分。

由教师带领分析施工流程与技术要点, 需要确定建筑装饰整体结构, 确定吊顶装饰技术要点与施工流程, 完成龙 骨与石膏板的安装与固定。吊杆安装组应完成材料与工具的准备, 并确定消防事项, 以项目设计方案为依据, 确认放 线、吊杆选材、吊杆固定流程以及各注意事项 ${ }^{[8]}$ 。龙骨安装组则应确认龙骨安装工艺与施工技术要点。石膏板安装组 应确认基层板安装、固定以及石膏板接缝处理流程和注意事项。灯带安装组应确认管线预埋安装及各注意事项。

每组同学均将所负责内容规划整理以后, 来进行学生与教师的讨论和分析, 完成具体施工方案的编写, 确定各项 目的施工方法以及施工流程。在该阶段中, 重要的是要培养学生独立思考以及相互协助的能力, 使其能够以理论知识 为支持，结合项目条件来编写出对实际施工具有指导意义的施工方案，使其能够更好的了解知识并利用知识 ${ }^{[9]}$ 。 
( 四) 项目检查与评价

在学习项目完成后, 需要组织进行检查和评价, 且检查主体依然为学生, 即由不同组别的学生根据所负责内容和 对知识的掌握情况进行分析研究, 由教师根据学生编制的项目方案和施工计划就其中问题进行提问, 确认其对知识的 掌握程度。并以组为单位, 对小组的表现进行客观评价和打分, 包括小组互评和教师评价, 使得学生对自身的情况有 一个全面的认识 ${ }^{[10]}$ 。

教师还应对学生进行综合评价，其扼要对需要提高的部分进行讲解，并强调项目需要注意的要点内容。

\section{五、结束语}

项目教学法在中专《建筑装饰施工技术》课程教学中应用意义重大, 可以更好的培养学生专业素养与综合能力, 以全新的教学模式, 来促使学生在掌握理论知识的同时, 对工程装饰施工技术与流程有更加全面深刻的认知, 这对于 提高学生专业能力至关重要。

\section{参考文献:}

[1]谈晨.高职室内设计专业《建筑装饰施工技术》课程教学改革实践[J].智库时代, 2019(45):281+284.

[2]梁杰,陈治.新形势下的《建筑装饰施工技术》课程教学改革实践[J].课程教育研究, 2019(40):41.

[3]宋利加.基于施工过程的建筑装饰施工技术实践教学分析[J].河南建材, 2019(02):283+287.

[4]肖斌, 吴佳泓, 于会泉.翻转课堂在高职装饰施工技术课程中的应用探究 [J]. 当代教育实践与教学研究, 2019(04):3940.

[5]刘林.装饰施工现场管理经验在《建筑装饰工程施工》实训教学中的运用 [J].城市建筑, 2019,16(02):152-153.

[6]孔祥峰.信息技术应用施工课教学过程的实践研究——以建筑装饰施工课为例[J]. 课程教育研究, 2018(51):68-69.

[7]邢艳春.高职建筑装饰工程技术专业实践教学体系构建研究[J].农村经济与科技, 2018,29(20):296.

[8]王丽.新形势下建筑装饰工程技术专业课程改革的研究[J].品牌研究, 2018(02):220-221.

[9]王丽,薛飞.新形势下建筑装饰施工技术课程改革的研究[J].西部素质教育, 2018,4(06):196.

[10]间帅平,张献梅.建筑装饰工程施工课程教学改革探索与实践 [J].济源职业技术学院学报, 2012,11(01):110-112. 